\title{
Juventude religiosa e homossexualidade: desafios para a promoção da saúde e de direitos sexuais*
}

\author{
Cristiane Gonçalves da Silva ${ }^{1}$ \\ Vera Paiva ${ }^{2}$ \\ Richard Parker ${ }^{3}$
}

SILVA, C.G.; PAIVA, V.; PARKER, R. Religious youth and homosexuality: challenges for promotion of health and sexual rights. Interface - Comunic., Saude, Educ., v.17, n.44, p.103-17, jan./mar. 2013.

This paper describes religious young people's conceptions of homosexuality, which is important knowledge for informing public policies within health promotion. Based on a constructionism and human rights framework, the study analyzed two focus groups and eighteen interviews with young followers of Afro-Brazilian religions (Umbanda and Candomblé), Catholicism, Anglicanism, Adventist Church of Promise and Assembly of God. Their conceptions about homosexuality took into consideration dogmatic morals and incorporated daily life experiences. Their interpretation of homosexuality therefore placed value on moral guidance from adult religious authorities and other forms of discourse relating to healthcare policies and social movements against sexual discrimination. To differing degrees, each young person reworked the discourse that had been accessed, as religious and sexual subjects. Within these psychosocial dynamics, openness towards health promotion based on human rights was observed, and youth people were seen as protagonists for adaptation of religious codes to singular courses of life and contexts.

Keywords: Youth. Religiosity. Homosexuality. Sexual health. Sexual rights.
Descreve-se como jovens religiosos concebem a homossexualidade, conhecimento relevante para informar políticas públicas no campo da promoção da saúde. Analisaram-se, com base no quadro construcionista e dos direitos humanos, dois grupos focais e 18 entrevistas com jovens de terreiros de Umbanda e Candomblé, em Igrejas Católica, Anglicana, Adventista da Promessa e Assembleia de Deus. As concepções sobre homossexualidade consideram a moral dogmática e incorporam a experiência viva e cotidiana. A interpretação da sexualidade homossexual, portanto, valoriza as orientações morais de autoridades adultas religiosas e outros discursos - os das políticas de saúde e dos movimentos sociais que defendem a não-discriminação sexual. Com intensidades diferentes, cada jovem reelabora os discursos acessados, como sujeito religioso e sexual. Identificou-se, nessa dinâmica psicossocial, abertura para a promoção da saúde baseada em direitos humanos, compreendendo jovens como protagonistas na adaptação de códigos religiosos a cada trajetória e contexto singulares.

Palavras-chave: Juventude. Religiosidade. Homossexualidade. Saúde sexual. Direitos sexuais.
- Elaborado com base em Silva (2010); pesquisa aprovada pelo Comitê de Ética em Pesquisa com Seres Humanos do Instituto de Psicologia, Universidade de São Paulo.

Departamento Políticas Públicas e Saúde Coletiva, Universidade Federal de São Paulo, campus Baixada Santista. R. Silva Jardim, 136, Vila Mathias. Santos, SP, Brasil. 11.015-020. cristiane.goncalves.silva@ gmail.com 2 Departamento Psicologia Social e do Trabalho, Instituto de Psicologia, Universidade de São Paulo.

3 Center for Gender,

Sexuality and Health, Mailman School of Public Health, Columbia University. 
JUVENTUDE RELIGIOSA E HOMOSSEXUALIDADE: ...

\section{Apresentação}

A religiosidade de usuários e trabalhadores do sistema público de saúde interfere nos cenários das práticas cotidianas deste sistema e nas políticas voltadas à saúde sexual e reprodutiva. Tanto a dinâmica psicossocial da religiosidade como sua expressão política podem determinar o curso das decisões no planejamento de programas de saúde, sustentando seu papel como instância reguladora da sexualidade e da reprodução.

No caso dos jovens, a maior parte das iniciativas para a promoção da saúde recomendadas pelo Ministério da Saúde e por organismos internacionais (OMS, UNICEF, UNESCO, UNAIDS) discute que ações educativas devem estimular o protagonismo dos jovens como detentores de autonomia para o exercício da sexualidade, para constituição dos relacionamentos afetivos e para tomar decisões no campo da reprodução. Antes disso, autores defendiam que direitos sexuais e reprodutivos são parte constitutiva dos direitos humanos, compreendidos como necessidade básica e parte dos direitos fundamentais (Ventura, 2003; Petchesky, 2001). O direito ao exercício da sexualidade implica: o direito de estabelecer relações homossexuais, o direito à proteção contra discriminação e de fazer parte de políticas públicas de promoção à saúde.

Essa perspectiva dos direitos sexuais enfrenta diferentes moralidades religiosas frente à sexualidade e à reprodução que têm ocupado lugar de destaque nos debates sobre políticas públicas no Brasil. Nas eleições do período 2010-2012, as controvérsias nesse campo estiveram presentes. Diante da maior visibilidade das relações afetivo-sexuais entre pessoas do mesmo sexo, legalizadas como família pelo Supremo Tribunal Federal em 2011, das ações contra a homofobia, houve recorrente posicionamento de lideranças cristãs no debate público eleitoral.

Por outro lado, a religiosidade viva tem uma dinâmica bem mais complexa. As religiões, como se sabe, estão entre as instituições que promovem discursos para a socialização, fornecem parâmetros para organização das sociedades e funcionam como orientadoras da vida cotidiana, além de constituírem redes de relações sociais. Alguns estudos (Martins, 2009; Duarte, 2006, 2005) têm indicado, entretanto, que os brasileiros têm grande abertura para negociar com a regulação religiosa dogmática na qual foram socializados ou à qual aderiram, e que suas convicções orientadas pela religião incidem nas decisões no âmbito privado com razoável autonomia. Desde a infância e, especialmente, durante a juventude, cada trajetória biográfica tem de dar conta do pluralismo de discursos oriundos das instituições e redes de pertencimento: família, escola, trabalho, amigos, comunidade religiosa, mídia, redes sociais, programas de saúde. A adesão religiosa marca a socialização, mesmo que isto não signifique, necessariamente, obediência total aos ditames doutrinários. É o ethos privado, também definido a partir do sistema religioso, que engloba a vida afetiva, conjugal, reprodutiva e erótica, que tem sido pano de fundo das negociações dos sujeitos entre linhas de força mais tradicionais e mais modernas (Duarte, 2005).

A forma como cada pessoa insere-se nas comunidades religiosas, como vive sua religiosidade, e o modo como constrói sua identidade religiosa no movimento de apropriação dos elementos necessários à satisfação de suas necessidades, assim como no afastamento dos elementos considerados inadequados para sua vida, são processos que a constituem como sujeito religioso. A comunidade religiosa compõe o mosaico de discursos com o qual jovens se deparam e têm de lidar nos momentos em que realizam suas escolhas, lidam com seus desejos, na forma como vivem ou viverão as experimentações afetivosexuais (Silva et al., 2008).

A dinâmica da religiosidade e o grau de afastamento de orientações mais ou menos dogmáticas, raramente, são considerados pelas iniciativas no campo da saúde, pelos programas intersetoriais voltados para a promoção de direitos na juventude e pelos movimentos sociais engajados na luta pela garantia dos direitos humanos.

Este artigo descreverá e discutirá concepções e posicionamentos de jovens religiosos sobre homossexualidade, considerando-os relevantes para informar políticas públicas para promoção da saúde sexual no quadro dos direitos humanos e apontar a proeminência da heteronormatividade na cultura dominada pela tradição judaico-cristã. 


\section{Métodos}

${ }^{4} \mathrm{~A}$ discussão deste artigo baseou-se em Silva (2010), tese elaborada com base na análise dos dados dos estudos: a) "Respostas Religiosas ao HIV/AIDS no Brasil", executado pela Associação Brasileira Interdisciplinar de AIDS (ABIA), sob a coordenação do Professor Doutor Richard Parker, com

financiamento do U.S. National Institute of Child Health and Human Development (1 R01 HD05118-01). O conteúdo do trabalho que aqui se apresenta é de inteira

responsabilidade da primeira autora, não representando a posição oficial do Eunice

Kennedy Shriver National Institute of Child Health and Human Development ou do National Institutes of Health (outras

informações sobre o estudo: http://

www.abiaids.org.br/); e

b) "Jovens e religião sexualidade e direitos entre lideranças católicas, evangélicas e afro-

brasileiras", financiado pelo Programa de Apoio a Projetos em

Sexualidade e Saúde Reprodutiva (PROSARE/ CCR/CEBRAP), do CNPq Entre os publicados anteriormente, este é o primeiro artigo que foca a homossexualidade. Ele analisa o conteúdo de algumas das entrevistas feitas durante o trabalho de campo realizado em 2008 e 2009, que contou com a participação de uma equipe de pesquisadores e com a atuação de agentes jovens (moças e rapazes das próprias comunidades religiosas participantes do estudo).

Os dois grupos focais $\mathrm{e}$ quatro das 18 entrevistas foram procedimentos exclusivos da pesquisa em questão.
O estudo analisou o conteúdo de 18 entrevistas em profundidade realizadas com jovens de 15 a 25 anos, sendo nove com rapazes (dois católicos, um adventista da promessa, um anglicano, um da Assembleia de Deus, dois umbandistas e dois do Candomblé) e nove com moças (duas católicas, uma adventista da promessa, uma anglicana, uma da Assembleia de Deus, duas umbandistas e duas do Candomblé). Analisou, também, o conteúdo de dois grupos focais, sendo um com a participação de quatro rapazes e nove moças umbandistas, e o outro grupo com a participação de cinco rapazes e quatro moças da Igreja Adventista da Promessa ${ }^{4}$.

Os participantes eram jovens ativos de distintas comunidades religiosas do município de São Paulo e de dois municípios da região metropolitana do ABCD que se encontravam na condição de estudantes, cursando o Ensino Médio. Aqueles com mais de 21 anos encontravam-se inseridos no mercado de trabalho, cursando o Ensino Superior. Os dados de caracterização socioeconômica coletados em campo (escolaridade, renda, moradia) permitem classificar os jovens participantes do estudo como pertencentes à classe média baixa.

As comunidades foram selecionadas a partir do envolvimento direto com questões relacionadas à prevenção do HIV/Aids e direitos para a juventude. Foram indicadas por lideranças religiosas e/ou profissionais de saúde envolvidos com o trabalho de prevenção e atenção ao HIV/Aids entre religiosos. Alguns dos jovens foram indicados por suas lideranças adultas, entrevistadas para outros estudos.

Os roteiros das 18 entrevistas e dos dois grupos focais abordaram: as carreiras afetivo-sexuais dos jovens, concepções sobre sexualidade, saúde sexual e reprodutiva e direitos, além da narrativa sobre a relação com suas autoridades religiosas em relação aos mesmos temas. Neste artigo, abordaremos apenas o tema da homossexualidade.

A análise e discussão levaram em conta o lugar que estes jovens ocupavam na comunidade religiosa de pertencimento e suas trajetórias de vida. Basearam-se na perspectiva construcionista e na sua produção sobre a sexualidade e sobre a dimensão psicossocial de práticas em saúde cuja abordagem está apoiada no quadro dos direitos humanos (Gruski, Tarantola, 2012; Paiva, 2012). No paradigma construcionista, gênero é uma categoria de análise social e a sexualidade é concebida como uma produção da cultura, assim como acontece com a homossexualidade, e têm características específicas em cada momento histórico e contexto intersubjetivo, em oposição ao paradigma sexológico que defende a natureza essencial de dois sexos e noções de um desenvolvimento psicossexual universal (Paiva, 2008).

O campo contrucionista, desde os anos 1990 no Brasil, tem concebido adolescência e juventude como um processo socialmente construído, e não como fase natural do desenvolvimento psicológico. Vários autores discutiram que essa é uma fase constituída por diferentes contextos sociais e culturais, que não se reduz ao que os textos clássicos chamam de "a" adolescência ou às características atribuídas universalmente a essa "fase do desenvolvimento" (Paiva, Ayres, França Júnior, 2004; Oliveira, 1999; Paiva, 1999). Essa perspectiva tem ressaltado que esta fase da vida comporta: diferentes experiências socioculturais e subjetivas, práticas sociais, carreiras sexuais e trajetórias pessoais (Heilborn, 2006).

Nessa abordagem, a noção de sujeito adotada nas práticas de saúde assume que cada pessoa também é sujeito de direito ao acesso à saúde integral de qualidade, à não-discriminação, à participação nas decisões sobre seu cuidado. Ou seja, a noção de sujeito sexual como categoria de análise (e não como entidade 
substantiva) implica entender cada pessoa como ativa condutora de sua biografia, e não como objeto de instintos, impulsos, ou apenas discursivamente assujeitada. Como sujeito sexual, tem-se que dar conta de diferentes discursos, em cada contexto intersubjetivo, que interpelam o posicionamento sobre vida sexual e reprodutiva. As pessoas abordadas pelo discurso técnico implicado nas práticas de saúde são concebidas como agentes da negociação consciente, e não objetos da pretensiosa manipulação técnica, muito menos, de qualquer moralização. Como sujeito sexual, cada pessoa é considerada portadora de direitos, cidadã que recorta e cola diferentes tradições culturais e discursivas, experiências rituais e normativas no exercício da sua sexualidade. Ao se conceberem as práticas de saúde como um encontro com pessoas que são sujeitos sexuais e de direito, espera-se investir nelas como agentes ativos da sua sexualidade, da prevenção e do autocuidado (Paiva, 1999).

As narrativas 5 compostas pelos jovens foram consideradas como a expressão dinâmica do posicionamento de pessoas interpeladas pelas questões propostas pelo estudo, tomadas como sujeitos plurais: sujeitos sexuais, sujeitos de direitos e sujeitos religiosos. O formato de grupo focal levou à apreensão, como esperado, das visões hegemônicas nos grupos estudados.

\section{Os jovens religiosos e a homossexualidade}

Muitos dos participantes do estudo não haviam começado a vida sexual e/ou afetiva. Entre aqueles com alguma vivência, três moças umbandistas relataram ter tido experiências homossexuais, enquanto todos os outros jovens religiosos, tendo ou não iniciado a vida afetivo-sexual, negaram ter vivenciado o desejo por alguém do mesmo sexo ou ter tido alguma relação homossexual, e fizeram questão de destacar sua heterossexualidade.

Os jovens que concebiam a homossexualidade como normal expressavam preocupação com a não-discriminação das pessoas com base em sua orientação sexual. Mesmo quando colocavam em oposição a "opção" sexual heterossexual e a "opção" homossexual, defendiam a ideia de que "todo mundo é igual" e que a discriminação seria inaceitável.

"Todos temos liberdade de escolha, se ela fizer essa opção pra ela. Elas vão ser felizes do jeito que elas escolheram. Só que longe de mim, assim, sabe? [...] Tem gente que não respeita, tem gente que bate. Eu não concordo com isso [...]". (Ivo, católico, 15 anos)

Alguns participantes afirmaram que suas comunidades religiosas, diante de adeptos assumidamente homossexuais, não reagiriam bem. Nos termos dos católicos, a Igreja reproduziria aquilo que ocorre na sociedade de maneira geral, ou seja, mostraria preconceito. Portanto, lésbicas, gays, bissexuais, travestis ou transexuais (LGBT) seriam discriminados ou, ao menos, objeto de riso, como relatou espontaneamente uma das católicas: "as pessoas iriam rir, mas não iriam discriminar [travesti na missa]". Por outro lado, os jovens católicos demonstraram, de forma enfática, preocupação com situações de discriminação e violência vividas por homossexuais. Também foram os católicos que mais radicalmente se afastavam da visão oficial das altas autoridades religiosas quando o tema era homossexualidade ou uso do preservativo para prevenção do HIV e gravidez.
${ }^{5}$ Ao longo do texto, as citações de palavras ou de trechos das narrativas dos jovens são apresentadas entre aspas e em itálico; os nomes são fictícios. 
“Eu acho assim: cada pessoa tem sua opinião de gostar, de não gostar. Mas não é o meu caso. [...] não vamos discriminar ninguém. Todo mundo é igual a todo mundo. Eu não discrimino". (Ana, católica, 16 anos)

“Eu acho que, pela influência católica é aquela história... o homem foi feito pra viver com a mulher e a mulher foi feita para viver com o homem. Mas eu não vejo problema nenhum [...]". (Caio, católico, 16 anos)

O conteúdo da narrativa dos jovens anglicanos confirmou que o repertório de significados sobre homossexualidade constitui-se a partir de cada contexto local e intersubjetivo, dinâmica mais complexa do que uma simples análise do dogma permitiria, além de confirmar a impossibilidade de apreender algo que expresse uma religiosidade igual para todos. Sua paróquia era também frequentada por uma rede de homens gays, algo pouco comum nos meios cristãos, colocando-os cotidianamente diante da diversidade sexual. Vivenciavam sua religiosidade, portanto, em um contexto onde a visibilidade e debate sobre homossexualidade havia contribuído para instaurar conflitos e dúvidas. A anglicana expressou preocupação com a não-discriminação e, ao mesmo tempo, explicitou sua dificuldade em conviver com o estilo de vida dos gays na Igreja. Temia que senhoras mais idosas ou novos frequentadores pudessem "dar de cara com casais gays de mãos dadas dentro da Igreja", e descreveu cenas em que considerou a troca de carícias e beijos entre gays inapropriada para o ambiente da Igreja. Seu namorado, estudante da teologia anglicana e alinhado com uma linha mais conservadora, teria sido alvo de brincadeiras e identificado como integrante de uma "paróquia gay" pelos colegas do curso. Quando descreveu o posicionamento da Igreja sobre homossexualidade, citou a não-aceitação da homossexualidade nos escritos bíblicos, ao mesmo tempo em que ressaltava a liberdade dos fiéis para concordar ou não com estas orientações. Já a narrativa do rapaz anglicano orientava-se pela linha teológica que não aceita a homossexualidade, concebendo-a "contra as leis de Deus e da natureza" e posicionando-se pelo respeito.

“Eu não sou a favor, mas eu respeito. São pessoas iguais a mim e eu tenho uma atitude de acolhimento com essas pessoas [...] Porque eu acho que vai contra a questão da própria natureza, a questão também da procriação. [...] [existe] uma ética cristã também, que eu acredito, que é contra nesse sentido. [...] Então, acredito que isso é contra a lei da natureza mesmo e contra a lei de Deus [...]". (José, anglicano, 23 anos)

O tema homossexualidade provocou reações distintas entre os jovens entrevistados: muitos compreendiam a sexualidade não heterossexual como algo "normal", outros compreendiam a homossexualidade como "pecado" ou como algo "não natural". O contraste mais forte foi observado entre posicionamentos dos pentecostais e umbandistas. Ao mesmo tempo, encontramos aproximações entre conteúdos das falas de jovens católicos e do Candomblé, especialmente quando enfatizavam sua identidade pessoal heterossexual ao mesmo tempo em que relatavam aceitação da homossexualidade. As visões de anglicanos e pentecostais expressavam mais fortemente a moralidade cristã tradicional, com as nuances marcadas pelo contexto de cada comunidade.

Entre os pentecostais, a concepção sobre homossexualidade constituiu-se fortemente a partir da estrutura sólida e "imutável" da "palavra" escrita na Bíblia, presente na interpretação dos jovens, repetida e reforçada por suas autoridades religiosas. Entendiam a homossexualidade como "pecado" e não demonstraram abertura para aceitar experiências sexuais não heterossexuais nas trajetórias biográficas dos adeptos. Referiram-se às escrituras sagradas para justificar seus posicionamentos e para marcar a diferença em relação à juventude "do mundo" - categoria nativa utilizada em referência aos jovens que não compartilham a crença evangélica. $O$ "mundo de fora" tem valores distintos do "mundo de dentro" constituído por irmãos e irmãs evangélicos para quem as questões como prevenção 
do HIV e de gravidez fora do casamento são consideradas menos importantes quando comparadas à relevância que têm para os jovens "do mundo". A reprodução de uma interpretação bíblica mais literal implicava a não-aceitação da homossexualidade entre os pentecostais, pois "foge ao propósito da criação". Mesmo com este significado, os pentecostais "acolhem" e "não condenam" os homossexuais. Entretanto, a atitude de acolhimento apareceu condicionada à mudança da orientação sexual de cada acolhido.

"Se você não deixa [a homossexualidade], você já não consegue viver a palavra de Deus. [...] os que não fazem esta renúncia, geralmente, não conseguem ficar na Igreja [...]. Eu conheço, por exemplo, homossexuais que deixaram de ser quando conheceram Jesus, quando aceitaram Jesus. Conheço e eles testemunham que realmente é difícil, mas que eles mesmos reconhecem que este não foi o plano da criação divina. Foi uma opção que eles fizeram antes. [...] Seja aonde quer que vá, a Bíblia, ela é única. Tem muitas traduções, mas a mensagem principal é a mesma. E, diante de Deus, isto não é aceitável ${ }^{6}$. Então a pessoa que quer, ela busca deixar a vida que outrora vivia. E eles testemunham que continuam sendo felizes, servindo Jesus, sendo héteros". (Camila, assembleiana, 25 anos)

Para os adventistas da promessa, determinadas visões científicas constitutivas do "mundo de fora", que definem a homossexualidade como doença, vão ao encontro da visão de sua religião, justificando o papel religioso de curá-la, combatê-la e eliminá-la. Também entre estes jovens foi identificada preocupação com a "não-discriminação", baseada numa noção particular de "acolhimento" que indicava que aqueles que compartilhavam desta fé "não aceitavam a homossexualidade, mas amavam os homossexuais". A concepção da homossexualidade como doença incluía relação de causa e efeito entre "abusos" e "traumas".

"Homossexualismo é pecado. É colocado aí, até do lado de fora já foi colocado que é uma doença [...] como a pessoa tem tendências a ser homem, outro tem tendências a ser mulher, outros têm tendência a, como se fosse um meio termo. Mas nós, pela palavra de Deus, nós entendemos que existe o homem e a mulher. A gente acredita que às vezes o homossexualismo é devido a uma formação familiar, é devido, às vezes, a abuso de crianças, na adolescência [...] nós amamos o homossexual, nós não discriminamos ele. É ele entrar dentro da Igreja e será bem-vindo, como todos os outros. Mas o que a gente condena é o homossexualismo. A pessoa, uma vez que ela entra aqui, nós vamos trabalhar, nós vamos conversar, nada de forçar, nós vamos conversar e mostrar e tentar reverter essa situação. Jesus amou o pecador e odiou o pecado". (Raul, adventista, 18 anos)

"[a homossexualidade] não agrada a Deus, é bíblico que os homossexuais não herdarão os céus. Não vai herdar a vida eterna. [...] Deus não aceita. Ele te ama, mas ele não pode te aceitar no reino dele do jeito que você é. Você tem que mudar. [...] Nunca escutei que uma pessoa aceitou Jesus homossexual e continuou homossexual. Porque, se ele veio pra Cristo, a verdade vai libertar ele, porque não é certo". (Vânia, adventista, 22 anos)
${ }^{6}$ Grifo para ressaltar o caráter "imutável" da palavra bíblica. 
No grupo focal com os adventistas da Promessa, foram citadas escrituras bíblicas, seus ensinamentos sobre a criação divina do homem e mulher e do plano divino para se juntarem e constituírem família, justificando classificar a homossexualidade como "errada" e "pecado". Um dos jovens pegou, abriu e indicou um trecho da Bíblia que carregava para provar que estavam a falar justamente aquilo que estava nas escrituras sagradas.

A afirmação constante de que não se devia "discriminar" os pecadores homossexuais foi elaborada de modos variados. Entre os quais, a comparação entre homossexuais, que "não herdarão o reino do céu", tal como ocorreria com os "mentirosos e os glutões". Não há dúvidas de que esta é uma comparação com pecados 'menores' que contrasta com outros discursos evangélicos que comparam homossexualidade à pedofilia ou zoofilia. Reconheciam que era muito provável que as pessoas que não queriam ou não podiam deixar a homossexualidade deixariam de frequentar a Igreja. Diante deste dilema, discutiram a possibilidade de o homossexual buscar locais que os aceitam, pois tinham conhecimento da existência de "Igrejas onde todos são homossexuais", fato que consideraram "uma abominação".

Em direção distinta, entre os jovens das religiões afro-brasileiras entrevistados e umbandistas participantes do grupo focal, houve indicações de aceitação e compreensão da homossexualidade como uma possibilidade de experiência e de escolha. Entretanto, dúvidas ou restrições que impediriam a aceitação, de fato, da diversidade sexual pela tradição religiosa e pelas divindades cultuadas (orixás e guias espirituais) apareceram nas falas dos umbandistas. Foi, sobretudo, a partir de exemplos de vivências de discriminação durante rituais religiosos e da ausência de referências dogmáticas explícitas sobre homossexualidade, que entendiam haver oscilação entre aceitar e reproduzir discriminação.

Para os jovens das religiões afro-brasileiras, as pessoas deveriam "ser felizes" do jeito que decidissem viver, homossexual ou não. Os rapazes umbandistas afirmaram que sua religião aceitava a homossexualidade com "certa normalidade" e lidava "com naturalidade" com pessoas LGBT. Um dos entrevistados não percebia, na Umbanda, a presença de um discurso direto sobre homossexualidade. Sua concepção era de que a sua religião "incluía" e "aceitava" muitas coisas, inclusive a homossexualidade.

"Eu nunca ouvi nenhuma autoridade lá, falando sobre esse assunto [homossexualidade], mas eu acho que trata com naturalidade. A Umbanda é uma religião que aceita, ela inclui muita gente, as pessoas de diferentes opções sexuais, não tem nenhum preconceito. Acho que ela aceita, assim como todas as outras pessoas". (Lúcio, umbandista, 22 anos)

${ }^{7} \mathrm{Na}$ Umbanda e no Candomblé, há filiação entre uma pessoa e divindades ancestrais - os orixás - que podem ser divindades masculinas, femininas ou mistas.

Neste sentido, esta explicação nativa está pautada na oposição/

inversão entre o gênero mítico e o gênero da pessoa, entendido e determinado a partir do sexo biológico.
Duas das moças umbandistas que relataram experiências ou desejos homossexuais e vivências com rapazes, compartilharam suas dúvidas em relação à aceitação da homossexualidade por parte da religião e divindades e, ao mesmo tempo, compartilharam uma explicação religiosa para a homossexualidade que costuma circular em "alguns segmentos" da Umbanda. Segundo essa visão, homens filhos de orixás femininos e mulheres filhas de orixás masculinos tenderiam a ser homossexuais ${ }^{7}$. Para jovens umbandistas e do Candomblé, a aceitação da homossexualidade depende diretamente da autoridade de cada Terreiro e, menos, do dogma e prática religiosos, transmitidos mais pela tradição oral que escrita. 
"[...] nossa religião não condena, mas ela não aceita. Vamos combinar, vamos ser sinceros, ninguém fala mal dos gays, mas ninguém aceita, também, não acha que é uma coisa normal. E eu fico muito confusa. Eu fico pensando, lá na frente, e se eu for homossexual, ou melhor, eu já sou. Não tem pra quem eu pergunte que aceite. Eu já perguntei para os guias, eu falei assim: "Escuta, pai, como que é?" [...] Ninguém me dá uma resposta concreta, sempre me falam que me aceitam. [...] eu continuo com a mesma dúvida". (Lia, umbandista, 18 anos)

No debate do grupo focal, umbandistas discutiram a capacidade de a religião dar sentido ao ato sexual, seja ele praticado com alguém do sexo oposto ou do mesmo sexo; demonstraram maior abertura para aceitação das relações afetivo-sexuais homossexuais, com sentidos e graus distintos para esta aceitação. Parte do grupo sentia que a Umbanda aceitava a diversidade sexual e outra desconhecia orientação religiosa sobre essa questão. Mas todos aceitavam como legítima a homossexualidade. Os distintos modos de umbandistas lidarem com a homossexualidade se relacionava, segundo eles, com a "linha de cada Terreiro", vinculada mais à postura de cada autoridade do que com a linhagem religiosa. Alguns destacaram que a religião "aceita na teoria", mas, na prática, avaliavam que a aceitação ainda era incompleta, algo do tipo "vai-não-vai". Interpretaram as normas da Umbanda como regras que permitiam aplicações diferentes das que foram previstas "na teoria". Reconheceram que a Umbanda se caracterizava por sua capacidade de adaptação e flexibilidade e, por outro lado, avaliavam como incompleta e imprecisa, tendo pouca difusão da doutrina entre os adeptos.

Os umbandistas reconheceram que muitos "adeptos que se assumiam homossexuais" foram aceitos de "uma forma muito bacana" na comunidade onde frequentavam. Apesar disso, houve relatos de "atitude de discriminação dentro da gira ${ }^{8 "}$ quando um adepto referiu-se de maneira irônica e em alto tom de voz sobre a homossexualidade de uma pessoa que havia sido atendida pelos guias espirituais. Concluíram que, embora a religião orientasse para que adeptos aceitassem e "amassem as pessoas como elas são", ainda reproduzia atitudes discriminatórias que persistem na sociedade.

Para os jovens do Candomblé, as concepções sobre homossexualidade estruturavam-se a partir da vivência do cotidiano dos Terreiros que frequentavam e de outros que conheciam. Todos os entrevistados fizeram referência à frequência de homossexuais no Candomblé9 quando trataram do tema. Argumentavam que gostar de alguém do mesmo sexo não é motivo para "discriminar" a pessoa, porque era "normal", "a pessoa quando nasce, já vem com aquilo". A percepção de que sua religião era mais aberta e inclusiva apareceu nas narrativas, apesar de reconhecerem a existência de limites para o estilo de vida dentro do Terreiro.

\footnotetext{
"Minha religião, ela é muito aberta. [...] Eu tenho a minha vida lá fora, lá fora eu ando do jeito que eu ando, mas aqui dentro eu tenho muito respeito. [...] minha religião é muito aberta. Se vem gay e ele quer frequentar, lógico que ele pode frequentar. (...) Não tem divisão de classe, se a pessoa é pobre, rico, de cor, também, entendeu? É uma religião, claro, vem dos afro-brasileiros, veio dos negros". (Régia, candomblecista, 15 anos)

“não diz nada [sobre homossexualidade], não tem nada escrito. [...] o Candomblé é muito aberto, ele não tem essa coisa de "não pode fazer isso, pode fazer aquilo, é proibido fazer isso, é proibido fazer aquilo". [...] o Candomblé tem muito homossexual, tem muito, muito. [...] às vezes o
}

${ }^{8}$ Gira é a denominação do ritual religioso praticado na Umbanda.

${ }^{9}$ Esta frequência grande de homossexuais no Candomblé é tema recorrente de estudos. Entre os pesquisadores destacamos Birman (2005, 1995, 1991) e Rios (2004). 
${ }^{10}$ Importante ressaltar que, apesar desta maior rigidez, a jovem anglicana oscilou entre a valorização do posicionamento de cada pessoa diante das posturas morais pregadas pela Bíblia e questionamentos sobre o comportamento homossexual. homossexual acaba se identificando mais com a religião, não sei se é exatamente isso... Mas tem muito homossexual na nossa religião". (Tadeu, candomblecista, 19 anos)

\section{Sujeitos, moralidades e direitos em diálogo}

Nas concepções sobre homossexualidade encontradas entre jovens católicos e das religiões afro-brasileiras, observou-se uma articulação entre valores laicos e religiosos no ethos privado não confessional, indicando a imprecisão das fronteiras entre o religioso e o não-religioso. No conteúdo das entrevistas dos pentecostais, ao contrário, verificou-se uma recorrente demarcação dessas fronteiras e invasão do discurso religioso nas dimensões do ethos privado não vinculadas diretamente à religiosidade. Todos os entrevistados expressavam-se como sujeitos que encontraram, no pertencimento religioso e na adesão pessoal, fórmulas pastorais com as quais concordavam, condições morais adequadas e a intensidade de ethos que consideravam de acordo com o estágio de vida no momento da realização do estudo, como já discutido por Duarte (2006).

Rapazes e moças católicos relataram que homossexuais fazem parte de suas redes de amigos(as) e parentes. No caso das comunidades de Candomblé e Umbanda, além das redes pessoais, contaram ter convívio com adeptos(as) ou visitantes LGBT nos rituais. Os anglicanos conheciam e conviviam com gays em sua comunidade, espaço que oferecia possibilidade de as pessoas professarem institucionalmente uma fé, mesmo com uma orientação sexual não heterossexual. Entre os pentecostais, não há relato de experiências diretas com LGBT em suas redes, e referiam-se a cenas vividas por amigos de outras Igrejas e, de acordo com seu repertório, homossexuais haviam se tornado heterossexuais ao "aceitarem Jesus"; e, no caso de persistirem em manter relacionamentos homossexuais, haveria impedimento para alcançar a "salvação, segundo a palavra de Deus". Tal como discutiu Natividade (2009a), em trabalho realizado com homens gays evangélicos, na Igreja é necessário "deixar o pecado de lado".

A compreensão dos entrevistados sobre o exercício da sexualidade como um direito foi variada. Católicos, umbandistas e candomblecistas valorizaram escolhas pessoais e reconheciam-se como sujeitos da sua sexualidade e de direitos, independentemente do posicionamento de sua religião. Os pentecostais e anglicanos, por outro lado, reproduziram e valorizaram o posicionamento religioso mais conservador para definir e adotar a forma ideal de viver a sexualidade ${ }^{10}$. Para todos os cristãos, a comunidade religiosa era um território importante de socialização, provedora de conhecimentos, promotora do acesso à informação e instrumental na reivindicação de direitos.

Entre os evangélicos pentecostais, identificou-se a existência de um código divino de conduta considerado o primeiro de todos os códigos, a partir do qual construíram seus posicionamentos sobre as questões relacionadas ao exercício da sexualidade e, portanto, sobre homossexualidade. Apesar do conflito existente entre o reconhecimento da legitimidade da não-discriminação das pessoas homossexuais e das orientações de religiosos que julgam-condenam as práticas homossexuais, não se pode deixar de ressaltar constante preocupação dos evangélicos com a não-discriminação, que, certamente, resulta de alguma participação da socialização em outros territórios "do mundo". Esta preocupação poderia ser apreendida como abertura para o diálogo sobre direitos sexuais e para o diálogo produtivo com gestores de políticas públicas de promoção da saúde sexual da juventude. Mesmo considerando a rigidez derivada de orientações morais que condenam a homossexualidade, reconheceram a possibilidade de 
outras leituras da Bíblia e a existência de outras denominações evangélicas inclusivas que reconhecem a diversidade sexual ${ }^{11}$ - possibilidade reconhecida, inclusive, pelos adventistas, com posturas mais heteronormativas entre os grupos abordados neste estudo.

Os umbandistas apresentaram concepções religiosas que resultaram de reelaborações de vários outros discursos, ou seja, apresentaram uma religiosidade difusa, híbrida, pouco dogmática, mas ainda religiosidade. Diferente dos evangélicos (históricos e penteconstais) e católicos, os umbandistas, aparentemente, não tinham orientações das autoridades religiosas que abordavam diretamente a homossexualidade, refletindo uma característica dessa religião o fato de não possuir diretrizes centralizadas nem mesmo para a prática ritual, como já discutiu Malandrino (2006). A bricolagem que caracteriza a Umbanda também caracterizou a forma como os jovens articularam e reelaboraram os discursos na construção de suas próprias concepções sobre homossexualidade. Os jovens umbandistas tendem a incluir a diversidade sexual entre os direitos dos jovens. Apesar disso, e justamente por causa fragmentação dogmática e da prática religiosa muito vinculada à interpretação de cada autoridade religiosa sobre a doutrina, não se pode afirmar que a Umbanda possua orientações religiosas que preconizam abertamente a aceitação da homossexualidade.

Este estudo indicou possibilidades de aproximação entre as experiências e concepções dos jovens religiosos e as concepções nas quais se baseiam os defensores dos discursos que promovem os direitos sexuais para a juventude no campo das políticas públicas de saúde. Moças e rapazes são capazes de conceber o sagrado e a homossexualidade de forma pessoal, expressando experiências socializadoras compartilhadas em sua geração, de acordo com os códigos religiosos em permanente reelaboração/reedição. No caso dos cristãos, cuja hermenêutica do texto escrito é orientação importante das práticas cotidianas, ainda assim há expressão de experiências socializadoras compartilhadas em sua geração. Ou seja, como sujeitos sexuais, os jovens religiosos constituem uma autonomia a partir da esfera da sexualidade organizada socioculturalmente por cenários sexuais específicos daquela comunidade religiosa, mas relacionados a um contexto cultural compartilhado com outros grupos e comunidades (Paiva, 2005). Cada adepto e adepta de uma religião é, ao mesmo tempo, sujeito religioso inserido em um contexto cultural e institucional que, por sua vez, é atualizado pelo domínio do sujeito sexual em interação com os outros para vivência da sexualidade e, de novo, interpelado pela religiosidade (Silva et al., 2008).

Os resultados deste estudo qualitativo permitem apenas a compreensão das comunidades pesquisadas, uma limitação deste estudo, e seria inadequado estender sua interpretação a outras, ainda que de mesma denominação. Os adeptos das religiões afro-brasileiras, de todo modo, parecem estar mais próximos do reconhecimento do exercício da sexualidade como um direito respeitado na comunidade religiosa e entendem suas religiões como "inclusivas". Esta visão parece relacionar-se com o processo histórico constitutivo do Candomblé e da Umbanda. Esta última, caracterizada como uma religião que se constitui da "mistura" da origem negra, indígena, católica, kardecista, e povoada por arquétipos que representam figuras marginais da sociedade brasileira - escravos, mestiços, índios, crianças - como divindades. (Silva, 2005). Já a tradição do Candomblé vê o corpo como mediador da vida, fonte de prazer, e os adeptos vivem a sexualidade como reconciliação dos desejos (Amaral,1992).

$\mathrm{O}$ acolhimento do homossexual pelos pentecostais condena moralmente a pessoa acolhida, ao conceber a homossexualidade como "pecado", pois, com isto, delega, para qualquer orientação não heterossexual, o fardo da ilegitimidade. Isto
${ }^{11}$ Por exemplo, a Igreja Cristã Contemporânea, a Igreja da Comunidade Metropolitana e a Comunidade Cristã Nova Esperança, citadas na entrevista com Marcelo Natividade (Natividade, 2009b). 
parece constituir-se como um dos maiores desafios para a implementação de políticas de saúde inclusivas, que devem enfrentar essas resistências para pautarem ações de promoção da saúde orientadas pelo horizonte político e ético dos direitos humanos. Jovens católicos expressam a força da tradição da Teologia da Libertação no Brasil e, mais especialmente, em São Paulo, onde o catolicismo alinha-se fortemente ao quadro dos direitos humanos desde 1960. Os dados deste estudo, portanto, fortalecem o argumento de outros pesquisadores que têm ressaltado a diversidade católica e sua maior abertura a modos variados de ser católico e de relacionar-se com os valores e práticas institucionais (Martins, 2009).

\section{Religião e religiosidade: ampliando o diálogo da saúde com religiosos e religiosas}

Esse trabalho ressaltou a distinção clara entre dogma e religiosidade viva no estudo de diferentes comunidades, assim como a resultante a ser observada na subjetivação e no plano individual, algo a ser considerado nas estratégias, ações e serviços constitutivos das políticas públicas de promoção da saúde. Permitiu reconhecer que o segmento da juventude religiosa se diferencia da juventude não religiosa, e mostrou que, de fato, a religião de escolha fornece uma visão de mundo com categorias próprias, confere motivos para a trajetória e modelos para a vida, como discutido por Geertz (1989). A religião opera categorias que constroem a subjetividade, impulsionam a ação, orientam e qualificam o comportamento externo e atitudes profundas (Sanchis, 2008).

Entre os jovens religiosos estudados, observa-se uma vida religiosa ao mesmo tempo idiossincrática e comunitária. A diversificação e o pluralismo reconhecidos na construção da identidade do sujeito sexual-religioso (com suas rupturas, deslizamentos e trajetórias singulares) só são perceptíveis quando se desloca a análise do discurso dogmático das religiões para sua realização implicada na subjetividade do indivíduo (Sanchis, 2001). No caso da promoção da saúde, se desloca, também, para a pessoa que é sujeito do direito à saúde integral, do direito à não-discriminação e ao acesso a informações e serviços de qualidade.

No esforço de construir políticas de saúde que entendam amplamente o processo saúde-doença implicado, também, em uma história social e atuem na garantia dos direitos sexuais e autonomia da juventude, é preciso levar em conta que as variações dos arranjos efetivados por jovens dependem do contexto. Este estudo mostrou que moças e rapazes se encaminham para uma ou outra combinação, ora há proeminência do sujeito sexual sobre o dogma, ora há predominância do dogma como saliente num sujeito também religioso.

A preocupação em evitar a discriminação ${ }^{12}$ entre os jovens sinaliza para a

${ }^{12} \mathrm{~A}$ preocupação com a não-discriminação aparece de forma significativa entre todos os jovens participantes do estudo e deve ser entendida nas suas nuances, a partir de seus contextos religiosos distintos. possibilidade de encontro com políticas públicas de saúde sexual pautadas nos direitos humanos. Qualquer política para a juventude, por sua vez, não pode reduzir jovens religiosos ao dogma, nem insistir em uma visão universal de juventude que perca de vista o sujeito plural interpelado a cada contexto. Reforçase a necessidade de se refinar o debate referente à religião como pertencimento institucional ou como crença e, mais ainda, enquanto um sistema de valores compartilhados (Rohden, 2005).

Entender o jovem a partir da noção de sujeito plural ajuda a compreendê-lo no manejo singular de diferentes discursos. Na perspectiva construcionista, é atributo, do que se nomeia sujeito, recriar, reeditar e reconstruir o sistema de crenças com base em sua própria experiência. Quando buscamos compreender a religiosidade do ponto de vista do sujeito religioso e plural, aumentamos as chances de se ter acesso à religião viva - que, de fato, é a que importa nas práticas de saúde - e 
não apenas aos sistemas de valores propagados pela hierarquia da instituição religiosa que forjam estereótipos, embora reconheça-se que tais aspectos sejam fundamentais para a legitimação e implantação de políticas.

Ao se abordar o jovem enquanto sujeito, valoriza-se sua capacidade de negociar mais conscientemente com os discursos oficiais da tradição religiosa e com a experiência de outros discursos presentes em sua vida cotidiana, inclusive com discursos sobre prevenção, sexualidade e direitos sexuais. O jovem também é marcado pelo diferenciador ético-moral dado pelo pertencimento a um grupo. A marca do pertencimento religioso pode existir independentemente da intensidade da adesão às ideias e práticas das instituições religiosas (Scott, Cantarelli, 2004), embora essa intensidade deva ser um elemento central a ser avaliado e respeitado nas abordagens em saúde.

O modo brasileiro de fazer política tem acirrado a manifestação aberta de moralidades religiosas que comprometem a efetivação da laicidade do Estado, fortalecem contextos favoráveis à reprodução do estigma, discriminação e vulnerabilidade, e evidenciam a tensão entre a defesa dos valores religiosos e as liberdades individuais quando se trata da sexualidade (Gomes, Natividade, Menezes, 2009).

Os resultados apresentados apontam para a potencialidade do diálogo estabelecido com as comunidades religiosas e conduzido sob a inspiração dos direitos humanos combinados aos princípios da laicidade. Este caminho pode ser capaz de superar desafios próprios desse diálogo, aumentando a possibilidade de interlocução. Mesmo quando a homossexualidade é classificada como pecado, como no caso de parte importante das religiões cristãs no Brasil, adeptos leigos (muitos deles trabalhadores da saúde) e autoridades religiosas precisam reconhecer a legitimidade destas experiências e que elas podem existir nas suas comunidades, entre seus adeptos, que devem ser entendidos como sujeitos de direito.

$\mathrm{O}$ estudo pretendeu compreender como a religiosidade de jovens articulou o debate sobre a homossexualidade, com o interesse em ampliar repertórios para proteção do direito de viverem a sua sexualidade de forma autônoma e informada, acolhida e protegida de estigma, discriminação e violência. Será mais interessante nessa perspectiva, portanto, considerar que, em qualquer circunstância, cada moça e cada rapaz é sujeito pleno e plural, regulador da experiência cotidiana no manejo de sua religiosidade, sujeito capaz de estabelecer diálogos entre o discurso religioso e os diversos discursos sobre sexualidade, inclusive o discurso dos direitos e das políticas públicas de saúde.

\section{Colaboradores}

Cristiane Gonçalves da Silva responsabilizou-se pela coleta de dados, análise, elaboração da primeira versão do texto e trabalhou na revisão de todas as versões do manuscrito; Vera Paiva responsabilizou-se pela supervisão da coleta de dados, parte da análise e considerações a partir da primeira versão do texto; Richard Parker responsabilizou-se por parte da análise e pelas considerações a partir das versões elaboradas pelas duas outras autoras. 


\section{Referências}

AMARAL, R.O. Ethos do povo de santo. In: candomblé. Rio de Janeiro: Pallas, 1992. p.57-75.

Xirê!: o modo de crer e viver no

BIRMAN, P. Transas e transes: sexo e gênero nos cultos afro-brasileiros, um sobrevôo.

Estud. Fem., v.13, n.2, p.403-14, 2005.

Fazer estilo criando gêneros: possessão e diferenças de gênero em terreiros de umbanda e candomblé no Rio de Janeiro. Rio de Janeiro: Relume Dumará, UERJ, 1995.

Relações de gênero, possessão e sexualidade". Physis, v.1, n.3, p.37-58, 1991.

DUARTE, L.F.D. Ethos privado e modernidade: o desafio das religiões entre indivíduo, família e congregação. In: Contracapa, 2006. p.51-88. et al. (Org.). Família e religião. Rio de Janeiro:

Ethos privado e justificação religiosa: negociações da reprodução na sociedade brasileira. In: HEILBORN, M.L. et al. (Orgs.). Sexualidade, família e ethos religioso. Rio de Janeiro: Garamond Universitária, 2005. p.137-76. (Coleção Sexualidade, gênero e sociedade).

DUARTE, L.F.D. et al. Família, reprodução e ethos religioso: subjetivismo e naturalismo como valores estruturantes. In: et al. (Orgs.). Família e religião. Rio de Janeiro: Contracapa, 2006. p.15-50.

GEERTZ, C. A religião como sistema cultural. In: A interpretação das culturas. Rio de Janeiro: Guanabara, 1989. p.101-62.

GOMES, E.C.; NATIVIDADE, M.; MENEZES, R.A. Parceria civil, aborto e eutanásia: controvérsias em torno da tramitação de projetos de lei. In: GOMES, E.C. (Org.). Dinâmicas contemporâneas do fenômeno religioso na sociedade brasileira. Aparecida: Ideias e Letras, 2009. p.188-210.

GRUSKIN, S.; TARANTOLA, D. Um panorama sobre saúde e direitos humanos. In: PAIVA, V.; AYRES, J.R.; BUCHALLA, C. (Orgs.). Da doença à cidadania: vulnerabilidade e direitos humanos. Curitiba: Juruá, 2012. p.23-42. v.1.

HEILBORN, M.L. Experiência da sexualidade, reprodução e trajetórias biográficas juvenis. In: _. et al. (Orgs.). O aprendizado da sexualidade: reprodução e trajetórias sociais de jovens brasileiros. Rio de Janeiro: Garamond Universitária/Editora Fiocruz, 2006. p.29-59.

MALANDRINO, B.C. Umbanda: mudanças e permanências - uma análise simbólica. São Paulo: EDUC/Fapesp, 2006.

MARTINS, A.D. Catolicismo contemporâneo: tratando da diversidade. In: GOMES, E.C. (Org.). Dinâmicas contemporâneas de fenômeno religioso na sociedade brasileira. Aparecida: Ideias e Letras, 2009. p.125-46.

NATIVIDADE, M. Ser homossexual ou ser evangélico?: dilemas de construção de identidade. In: GOMES, E.C. (Org.). Dinâmicas contemporâneas de fenômeno religioso na sociedade brasileira. Aparecida: Ideias e Letras, 2009a. p.101-24.

Igrejas inclusivas: Entrevista [13 jan. 2009]. Entrevistador: O. Hirsch. Rio de Janeiro: Clam - Centro Latino-Americano em Sexualidade e Direitos Humanos, 2009b. Disponível em: <http://www.clam.org.br/publique/cgi/cgilua.exe/sys/ start.htm?infoid $=5032 \&$ sid $=43>$. Acesso em: 18 out. 2009.

OLIVEIRA, M.C. Cultura, adolescência, saúde: Argentina, Brasil, México. Campinas: Consórcio de Programas em Saúde Reprodutiva e Sexualidade na América Latina (CEDES/COLMEX/NEPO-UNICAMP), 1999.

PAIVA, V.; AYRES, J. R.; FRANÇA JUNIOR, I. Expanding the flexibility of normative patterns in youth sexuality and prevention programs. Sex. Res. Soc. Pol. J. NSRC, n.1, p.1-15, 2004. In: KOGA, D. (Org.), p.157-85, 2008. 
PAIVA, V. Cenas da vida cotidiana: metodologia para compreender e reduzir a vulnerabilidade na perspectiva dos direitos humanos. In PAIVA, V.; AYRES, J.R.; BUCHALLA, C. (Orgs.). Da doença à cidadania: vulnerabilidade e direitos humanos. Curitiba: Juruá, 2012, v.1, p.165-208.

Analysing sexual experiences through 'scenes': a framework for the evaluation of sexuality education. Sex Educ., v.5, n.4, p.345-59, 2005.

Cenas sexuais, roteiros de gênero e sujeito sexual. In: BARBOSA, R.M.; PARKER, R. (Orgs.). Sexualidades pelo avesso: direitos, identidade e poder. Rio de Janeiro: IMS/UERJ; São Paulo: Editora 34, 1999. p.250-71.

PETCHESKY, R.P. Derechos y necesidades: repensando las conexiones en los debates sobre salud reproductiva y sexual. In: GRUSKIN, S. (Org.). Derechos sexuales y reproductivos: aportes y dialogos contemporaneos. Lima: Centro de la Mujer Peruana Flora Tristán, 2001. p.27-41.

RIOS, L.F. O feitiço de Exu: um estudo comparativo sobre parcerias e práticas homossexuais entre homens jovens candomblecistas. 2004. Tese (Doutorado) Instituto de Medicina Social, Universidade do Estado do Rio de Janeiro, Rio de Janeiro. 2004.

ROHDEN, F; Equipe Gravad. Religião e iniciação sexual em jovens de camadas populares. In: HEILBORN, M.L. et al. (Orgs.). Sexualidade, família e ethos religioso. Rio de Janeiro: Garamond Universitária, 2005. p. 77-206.

SANCHIS, P. Religiões, religião: alguns problemas do sincretismo no campo religioso brasileiro. In: (Org.). Fiéis e cidadãos: percursos de sincretismo no Brasil. Rio de Janeiro: UERJ, 2001. p.9-58. p.71-92, 2008.

Cultura brasileira e religião...: passado e atualidade... Cad. CERU, v.19, s.2,

SCOTT, R.P.; CANTARELLI, J. Jovens, religiosidade e aquisição de conhecimentos e habilidades entre camadas populares. Cad. CRH, v.17, n.42, p.375-88, 2004.

SILVA, C.G. Sexualidade, conjugalidade e direitos entre jovens religiosos da região metropolitana de São Paulo. 2010. Tese (Doutorado) - Departamento de Psicologia Social e do Trabalho, Instituto de Psicologia, Universidade de São Paulo. 2010. Disponível em: <http://www.teses.usp.br/teses/disponiveis/47/47134/tde24042010-114038/pt-br.php>.

SILVA, C.G. et al. Religiosidade, juventude e sexualidade: entre a autonomia e a rigidez. Psicol. Estud., v.13, n.4, p.683-92, 2008.

SILVA, V.G. Candomblé e Umbanda: caminhos da devoção brasileira. 2.ed. São Paulo: Selo Negro, 2005.

VENTURA, M. et al. Princípios dos direitos sexuais e reprodutivos. In: (Orgs.).

Direitos sexuais e direitos reprodutivos na perspectiva dos direitos humanos: síntese para gestores, legisladores e operadores do direito. Rio de Janeiro: Advocaci, 2003. p.49-54. 
SILVA, C.G.; PAIVA, V.; PARKER, R.

SILVA, C.G.; PAIVA, V.; PARKER, R. Los jóvenes religiosos y la homosexualidad: desafíos para la promoción de la salud y de los derechos sexuales. Interface - Comunic., Saude, Educ., v.17, n.44, p.103-17, jan./mar. 2013.

En ese artículo se describe cómo jóvenes religiosos conciben la homosexualidad, conocimiento relevante para informar políticas públicas en el ámbito de la promoción de la salud. Con base en referencias constructivistas y de los derechos humanos, fueron analizados dos grupos focales y dieciocho entrevistas con jóvenes de Umbanda y Candomblé, Iglesias Católica, Anglicana, Adventista de la Promesa y Asamblea de Dios. Las concepciones sobre homosexualidad consideran la moral dogmática incorporando la experiencia cotidiana. La interpretación de la sexualidad homosexual, por lo tanto, valoriza orientaciones morales de autoridades religiosas y discursos de las políticas de salud y de los movimientos sociales que defienden la no discriminación sexual. Con intensidades diferentes, cada joven reelabora los discursos accedidos, como sujeto religioso y sexual. Se identificó en esa dinámica psico-social, apertura para la promoción de la salud con base en derechos humanos, comprendiendo jóvenes como protagonistas en la adaptación de códigos religiosos a cada trayectoria y contexto singulares.

Palabras clave: Jóvenes. Religiosidad. Homosexualidad. Religión y sexo. Derechos sexuales. 